\title{
The Need for Economic Cooperation among Developing Countries
}

\section{Helen O'Neill}

\section{The UNCTAD Resolution}

Among the components of the programme of action for the implementation of NIEO, none is more innovative than that calling for increased collective self-reliance (CSR) or economic cooperation among developing countries (ECDC). ${ }^{1}$ The resolution on ECDC (UNCTAD 1979) which was unanimously agreed at UNCTAD $V$ was one of the more positive achievements of the conference. It resolved to convene a special session of the UNCTAD Committee on ECDC early in 1980 in order to examine the studies carried out by the UNCTAD Secretariat on ECDC and to consider the ldcs' proposals in certain priority areas, and to take appropriate action. In pursuit of these aims, and with an unprecedented departure from the UN 'universality' principle, the Secretary General of UNCTAD was requested to provide the necessary technical support, conference and secretariat services for three preparatory meetings of ldc or other government experts. The specified priority areas were: the establishment of a global system of trade preferences among ldcs; cooperation among state trading organisations (STOs) of ldcs; and the establishment of multinational marketing enterprises among ldcs.

The UNCTAD Secretariat was also requested 'to intensify and complete' its ongoing activities and to submit to the Committee on ECDC actionoriented proposals based on the Arusha Programme for Collective Self-Reliance drawn up by the Group of 77 at their pre-UNCTAD V Ministerial Meeting held in Arusha in February 1979 (UNCT AD (1) 1979). These proposals were to cover:

-the elaboration, operation and maintenance of a trade information system regarding the foreign trade of ldcs, taking into account the continuing work in the UNCTAD/GATT International Trade Centre and other international organisations;

\footnotetext{
1 CSR and ECDC are used fairly interchangeabiy in this article since the focus is on the strategy-or action-oriented aspect of the CSR concept. However, since self-reliance may be be considered as a legitimate end in itself, and since it inherently contains a collective element (this is what distinguishes it from the self-help concept which is inherently individualistic) then in the broadest interpretation of CSR. ECDC would be contained within it, but would not coincide with it. In short ECDC may be viewed as means, whereas CSR may be viewed as both means and end.
}

- the preparation and up-dating of a handbook of STOs of ldcs and a continuation of such technical assistance activities as seminars and consultancy services for individual state trading organisations;

-the provision of technical assistance to projects for ldc multinational marketing arrangements;

-the provision of assistance for relevant aspects of monetary and financial cooperation among ldcs;

- the analysis and identification of opportunities for establishing and promoting joint marketing ventures among ldcs;

-the intensification of its activities, in collaboration with UNIDO, to promote multinational production enterprises among ldcs.

\section{Self-reliance as a Conceptual and Strategic Approach}

CSR reflects the desire on the part of the ldcs to decrease their dependence on the developed economies; that is, to rely more on themselves, on their own resources, and on their own vision of 'development' in order to promote the welfare of their people. It also reflects disillusion with the benefits to be derived from a continuation of the quantity, and more especially the quality, of their existing links with the industrialised countries. Finally, it reflects the hope that, by strengthening cooperative links with each other, they may improve their position within the international economic order and thereby promote their development. As a strategy, CSR may be described as all or part of that package of policies involving cooperation between the ldcs in fields such as production, trade, investment and finance, which they believe will enhance their self-reliance and promote their development.

CSR embodies two distinct notions of unity; first, the idea of uniting against an outside group to force concessions through increased solidarity and bargaining power, and second, that of uniting with others in a similar predicament, to solve common problems collectively. Therefore, as a strategy, CSR has two components: first, policies designed to increase the power of the 
Third World; and second, the more 'developmental' package, consisting of policies in the fields of production, technology, finance and trade, whose objective is the long-term development of the cooperating ldcs. While the latter aspect of CSR is more important (both for ldcs and for the world as a whole), the former is more urgent.

A critical element in Third World power is control over resources. Ldcs need to transform the control they have at present over their resources into some measure of influence over the industrialised countries, over TNCs, and over events in the global economy. However, an existing constraint on the development of Third World power is the lack of cohesion of the Third World itself; at this juncture it is more a wish than a reality. Marc Williams (above) examines the strengths and weaknesses of the Group of 77 , while Vincent Cable examines the various attempts at regional groupings among ldcs. This article concentrates on CSR as a long-term development tool and considers, first, some of the proposals that have been made to foster ECDC, and then the existing production and marketing arrangements for six commodities to illustrate both the need for ECDC and the strength of the vested interests that are likely to oppose it.

\section{Proposals on ECDC and CSR}

A comprehensive set of measures and objectives designed to promote cooperation between ldcs had already been suggested in the Programme on ECDC adopted at the Conference of the Group of 77 held in Mexico City in September 1976, and in the Arusha Programme for Collective SelfReliance drawn up by the Group of 77 at their pre-UNCTAD V Ministerial Meeting, held in Arusha in February 1979. Perhaps most usefully, the UNCTAD Secretariat studies referred to in the UNCTAD V ECDC resolution and described at some length below, have identified eight key elements which could be included in a comprehensive CSR strategy. These are: a global system of trade preferences among developing countries (GSTP); cooperation among STOs; multinational marketing and production enterprises; monetary and financial cooperation; strengthening subregional, regional and inter-regional schemes of ldc economic cooperation; special favourable treatment for the least developed island and landlocked ldcs; cooperation in the transfer and development of technology; and cooperation in the insurance sector.

The proposals for a GSTP aim to promote national production and mutual trade by exploiting emerging complementarities among Idcs. The importance of STOs lies in their capacity to implement ECDC and CSR through joint procurement of imports, market research, promotion of non-traditional exports and operating joint facilitation centres in terminal markets. All these trade measures need to be accompanied by monetary and financial arrangements to cover multilateral payments and clearing arrangements, trade financing facilities, and capital and financial flows. A coordination committee on multilateral payments arrangements and monetary cooperation among ldcs which held its first meeting in July 1978 in Bangkok, is designed to promote such cooperation.

\section{Constraints on the Implementation of ECDC Strategies}

What are the prospects for implementing these elements of ECDC in the medium term? If ECDC and CSR represent an attempt on the part of the ldcs to alter their dependency status within an interdependent global economy, then their present levels of dependency will operate, not only as a spur to the initiation of ECDC, but also as a constraint on the implementation of such strategies. An important part of the failure of past regional integration schemes can be ascribed to the asymmetrical nature of the global economy. This is true even of failings that at first sight appear to be internal to the Idcs as a group, such as weakness of political will, inadequate distribution between members of costs and benefits, the insignificance of intra-regional trade, disintegration of convertibility areas, the absence of adequate dispute settlement machinery, and reliance on conventional theory and institutional arrangements for structuring regional integration schemes. Any search for manifestations of dependency and constraints on the implementation of CSR strategies should start by examining the evidence relating to eight key questions: what goods are produced, how, and by whom, who finances production, for whom are the goods produced, what goods are traded, how are world prices determined and how are the goods traded?

The series of UNCTAD studies on primary commodities, manufactures and invisibles has addressed these questions. They support the view that the ldcs are the dependent partners. TNC producing and marketing activities place production, pricing, marketing and distribution, transportation, and the operation of futures markets, largely beyond the control of the ldcs in many important branches of economic activity. CSR strategies, if successfully implemented, could 
help to reduce these external controls, but by the same token, the existence of the controls constitutes a constraint on the implementation of CSR strategies. We turn now to the case material of the UNCTAD studies.

\section{The banana industry ${ }^{2}$}

International trade in bananas is integrated in the sense that a few large companies are dominant in several stages of production and distribution. Seventy per cent of world trade is controlled by three TNCs; United Brands (35 per cent), Standard Fruit (25 per cent) and Del Monte (10 per cent). With the exception of Ecuador, the large-scale foreign-owned plantation unit has been a dominant feature in Latin America and the Caribbean (UNCTAD 1978:21). In the case of both the United Fruit Company (UFC) in Central America and its main competitor Castle and Cooke (a large food conglomerate which owns 84 per cent of the shares of Standard Fruit), bananas are only one of a number of products

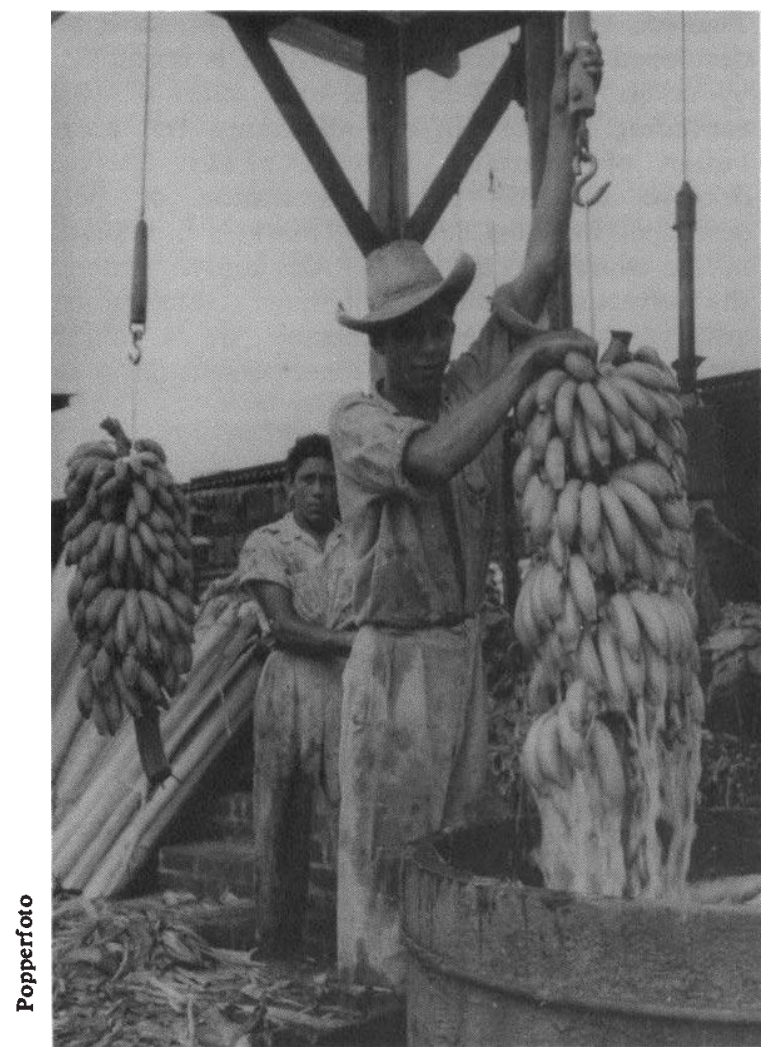

Banana washing station in Escuintla, Guatemala.

2 This section is based on UNCTAD (1978). produced on their enormous land holdings in a large number of countries in the region. Growth and rapid diversification have been characteristic of the three large TNCs and as a share of their total sales, bananas have decreased in importance.

Because of the vertically-integrated nature of the TNCs, their influence dominates not only production but also pricing, and marketing and distribution. Competition among them for larger shares of the world market has apparently contributed to a decline in real prices. Companies have also pursued policies designed to obtain a low fob price to assure a larger mark-up on sales to ripeners and wholesalers (UNCTAD 1978: 30). The terms of trade for bananas in relation to manufactures declined by approximately 60 per cent between 1954 and the end of 1973. These price declines benefited consumers in the developed countries and deprived producers of the benefits of cost-reducing innovations. In contrast, some countries have been forced to give production subsidies to counteract rapid increases in the cost of fuel, transport and distribution.

As a result, according to the UNCTAD study, there has been a net transfer of real resources from the continuing producing countries to the developed consuming countries. The declining terms of trade, which caused this income drain, were the result of the tendency of export availabilities to increase relative to import demand, and of the domination and control of the marketing and distribution system by TNCs. Virtually all banana exports from Central America and the Philippines, and about 50 per cent of Ecuador's exports, are controlled by TNCs. Even greater domination is exercised at the import end where they control over 60 per cent of total imports into the developed countries. UNCTAD's estimates indicate that the share of the local growers in the final retail price is of the order of 11 per cent. TNC gross revenues, excluding ripening, are about 35 per cent. In addition to the income drain, there may also be development-distorting effects. Historically, banana production for the world market has been, and still continues to be, almost exclusively a plantation industry. Very large tracts of the most fertile land in the producing countries are owned by the plantations. The question arises: given the low returns which accrue to the producing countries in total and the very small number of local people who benefit under the prevailing pattern of trade (UNCTAD 1978: 79), is this a rational use of the scarce land resources of Latin American countries? 


\section{The tobacco industry ${ }^{3}$}

Control by US- and UK-based TNCs permeates the entire tobacco industry. The source of the power of the seven large tobacco TNCs (TTCs) lies in their control of world cigarette manufacturing. These TTCs are vertically integrated through all the stages of production, marketing, and distribution, and horizontally integrated, not only with other commodity sectors of the world market but also with a variety of other activities including manufacturing, mining, banking, insurance, shipping, communications, and services.

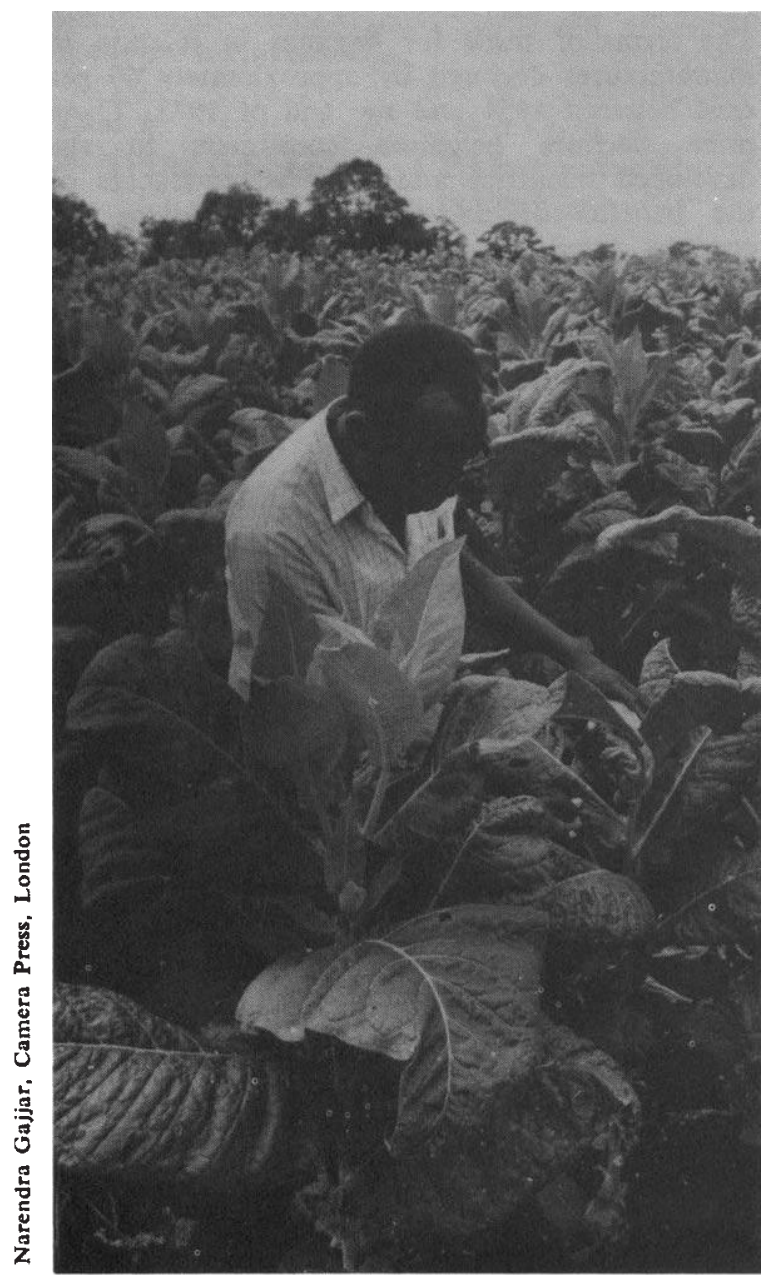

Tobacco field in Zanzibar.

3 This section is based on UNCTAD (1978a).
Leaf tobacco is grown and marketed in many countries. The bulk of output is from small-scale, labour-intensive peasant farming and share cropping. About $15 \mathrm{mn}$ peasants and small farmers grow leaf tobacco. While production is dominated by four countries-China, the USA, India and the USSR - more than half of the leaf tobacco which enters international trade emanates from the ldcs. However, in contrast to bananas, most tobacco produced outside the centrally-planned economies becomes, in the words of the UNCTAD study, "caught in the transnational web' even if it never enters international trade because, in most ldcs, 'domestic' tobacco plants are controlled by the TTCs (UNCTAD 1978a: 106). Six major industrialised trading areas and countries account for about 85 per cent of tobacco leaf imports. This trade is almost completely controlled by six transnational leaf buyers inter-linked with the TTCs who also, with few exceptions, control the maritime transport used in the movement of raw tobacco.

Tobacco manufacturing in the non-socialist developed and developing countries is dominated by seven large TTCs with total sales in 1976 exceeding $\$ 32 \mathrm{bn}$. In the marketing and distribution of cigarettes, the TTCs also exercise decisive control. Their penetration of both developed and less developed markets is realised, in the words of the UNCTAD study, 'through the advertising complex of large transnational advertising agencies, harnessed to a highly sophisticated network of mass-persuasion technology' (UNCTAD 1978a: 82).

In addition to transfer pricing and repatriated profits, there is a further income drain and development distortion from the operation of TNCs in the ldcs. These corporations have borrowed domestic capital to meet their business requirements. TNCs compete with local industry for domestic savings. Through the medium of the transnational banking system, they gain access to local finance which, in many instances, enables them to take over local firms whose access to funds is more limited. As the UNCTAD study points out, linkages between the big banking corporations and the tobacco conglomerates are common. It adds that between 1960 and 1970 , approximately 78 per cent of manufacturing operations of US corporations in Latin America were financed by domestic capital. For the TTCs, an estimated 90 per cent of their aggregate investments in Latin America was financed by domestic capital (UNCTAD 1978: ch. 1, section E). 


\section{The cotton futures market}

Developing countries regard price instability as a serious disadvantage of primary commodity production. Consumers of primary products in the developed economies (who are often producers of manufactured goods) are, likewise, concerned about the effects of commodity price instability. Activity on futures markets reflects these concerns.

The participants on the commodity futures markets are hedgers and speculators. The former buy and sell futures contracts to counteract the impact of future price fluctuations on the value of physical purchases and sales of commodities. Speculators enter the market in order to exploit price swings and make a profit. An UNCTAD study (UNCTAD 1978b) of the cotton futures market highlights the dependent position of the developing commodity-producing economies in world commodity markets. The most important hedgers on the cotton futures market are the giant cotton-trading conglomerates. Approximately 15 large multi-product corporations handle 90 per cent of globally traded cotton. These corporations have linkages with the raw cotton and textile industries, and with finance capital, and play a dominant role in trading in other commodities.

The giant multi-commodity traders engage in both hedging and speculation, helped by the efficient commodity intelligence network they possess (which is unavailable to most producers). They also engage in manipulative practices such as 'long squeezes' whereby they 'corner' or control a large proportion of the futures contracts and of the deliverable cotton supplies and then use these two types of control to alter futures prices. In the words of the UNCTAD study, 'The cotton futures market has become a trading mechanism whereby large traders, individually or through collusive manipulative practices, can acquire substantial gains and, in so doing, destabilise prices' (UNCTAD 1978b: 13). Thus, far from contributing to the free interplay of supply and demand and to stabilising prices, the futures markets, when controlled by the great multi-commodity traders, are a source of domination and instability.

\section{The electrical industry}

The importance of the electrical industry in the industrialisation of the ldcs and in their potential to implement CSR strategies rests on the size of the industry, the nature of the product (capital and consumer goods), its technology and the way in which technology is acquired, the difficulties associated with establishing and maintaining indigenous firms, and the general pervasiveness of restrictive business practices in international markets. The industry consists of a wide range of firms producing capital goods (equipment for generation, transmission and distribution of electricity) and consumer goods (household appliances and electronic products). In a study undertaken for UNCTAD, Newfarmer (1978) states that the industry can be described as concentrated in the sense that the leading 20 TNCs produce most of the industry's sales and control most of its advanced technology. These leading firms are interrelated: within markets, in equity cross-holdings, in joint ventures, in licensing arrangements to share technology, in consortia and in cartels.

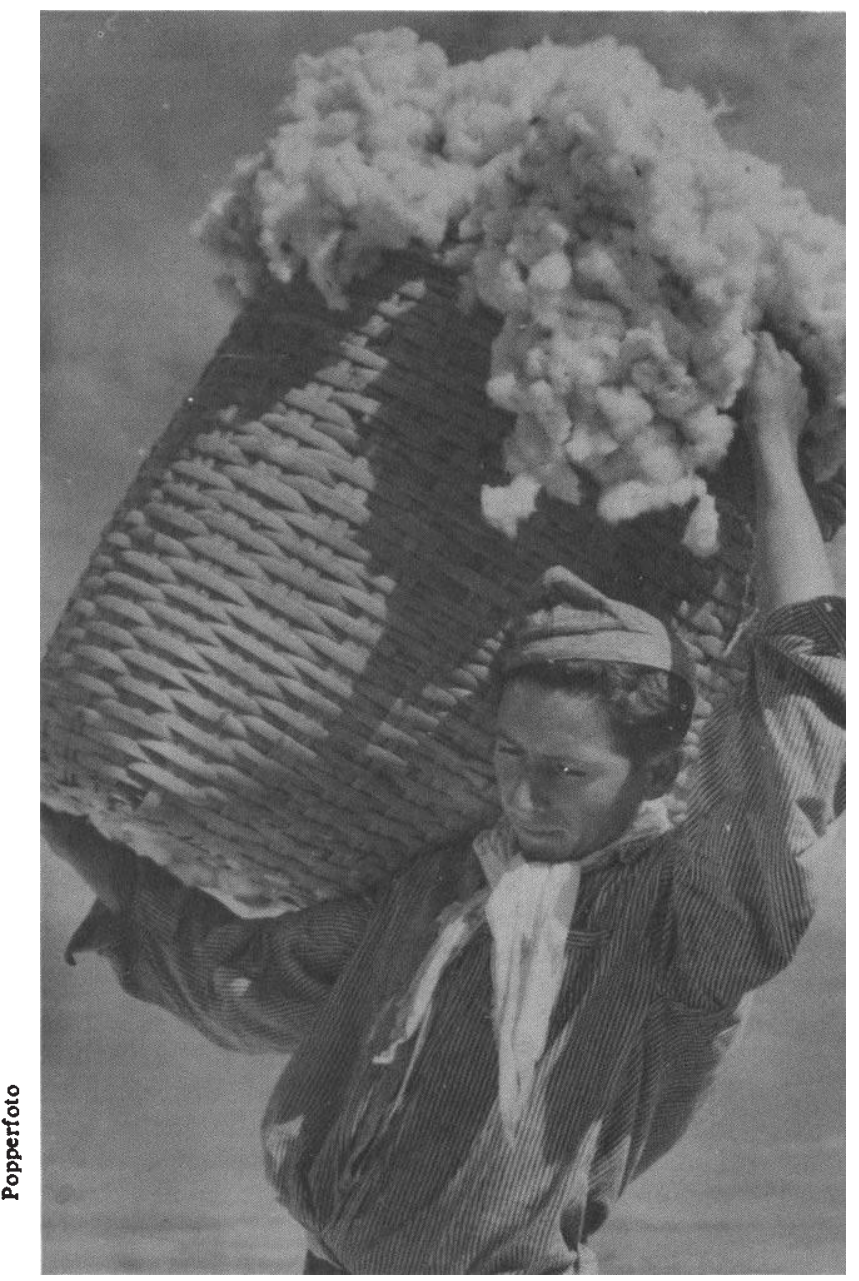

Brazilian worker carrying a basket of freshlypicked cotton. 
From the beginning of the present century, restrictive practices have operated to restrain competition, divide up the world market, and control the flow of technology. Cross-licensing contracts and cartels raised barriers to entry in countries outside the pioneering ones, especially ldcs. As a result, growth in the electrical industry tended to lag behind the general progress of industrialisation in ldcs up to the Second World War. The concentrated structure of international production and the associated restrictive practices limited competition and led to monopoly profits which 'served to shift investible surplus from the developing periphery to the industrialised centre' (Newfarmer 1978: 166).

The growth of protection in the ldcs during the early stages of import substitution industrialisation (ISI) raised barriers to imports and induced TNCs to invest in ldcs to hold their markets. This did not necessarily reduce imports, particularly during the early stages of ISI. It substituted imports of intermediate products and heavy machinery from the parent TNC for finished products.

Newfarmer cites three ways in which the international market power of the TNCs affects the structures of investment and development. The first is the creation of spheres of influence in the location of investment which restricts entry, produces monopoly profits, and recreates the concentrated market structures of the investing country. The second is the takeover of local firms and denationalisation of the industry in the ldc; from the point of view of the TNCs this reduces competition, but from the point of view of the host country, distorts the pattern of development by reducing indigenous investment and confining the local income flow to wages, instead of wages and profits. According to Newfarmer, this takeover process becomes more frequent as development advances. In Latin America for example, 42 per cent of US electrical TNCs established subsidiary operations by acquiring an existing domestic firm in the $1958-68$ period. In Mexico, 60 per cent of such TNCs established their operations through takeover, and in Brazil takeovers accounted for almost the whole of the substantial increase in the foreign share of the electrical industry between 1960 and 1974. In Brazil local firms which were not taken over went bankrupt because they fell behind in the technology race, or were driven out of business by predatory pricing. The survival of indigenous firms was not helped by the fact that USAID loans and European development loans for heavy electrical investments were tied to imports of electrical plant manufactured in the lending country (Epstein and Mirow 1977).

The third distortion is the impact on profits of concentration and product differentiation. These tend to move positively with each other and to reduce the efficiency of the economy through eroding the allocative function of the price mechanism. Import and export trade in electrical goods is controlled by the TNC. Intra-firm trade between the investing country parent and the periphery subsidiary supplies intermediate and capital goods which the latter is not geared (or allowed) to produce. These sales, conducted at transfer prices, result in the shifting of income flows between the countries in which the TNC operates at rates and in quantities which reflect the global policy of the parent company with respect to the most advantageous location of declared profit, given the tax, exchange control and investment opportunity structures of the various countries.

In addition, interdependence and cartelisation among the TNCs (frowned upon within the developed countries but permitted by them when it relates to exports) leads to inflated prices for some imports, aggravating general inflationary pressures and balance of payments problems. Spheres of influence agreements with respect to markets and investment locations, and barriers to entry into developed country markets effectively prevent the ldcs from exporting electrical goods unless it suits TNC interests. As Newfarmer points out, the expansion of trade can benefit both the TNCs and the ldcs. However, the use of restrictive practices distorts the distribution of the gains from trade between the two parties in favour of the former.

\section{Shipping}

Maritime transport is an important element in the effort to increase the links between ldcs, and therefore in any progress they may make towards CSR. The ldcs account for over 60 per cent in volume of world ocean cargo. Yet in 1948 they owned merely 4 per cent of the world fleet; by 1970 this figure had only increased to 7.6 per cent.

The ability of ldc lines to influence Liner Conference operation will increase soon with the coming into force of the UN Code of Conduct for Liner Conferences. An important principle of the Code is that it would give 'rights' to each partner in a trading agreement to carry a certain percentage of the goods (40 per cent to the 
exporter's lines, 40 per cent to the importer's and a 'significant share' of the remainder to third flags). It would also institutionalise the process of consultation between Conferences and shippers (the exporters and importers) on the determination of freight rates. One disadvantage which most of the ldcs suffer at this stage in their development arises from the fact that manufactured goods are relatively new exports for them. New items are charged "not otherwise specified' (nos) rates which tend to be significantly higher than average. In addition, the headquarters of the Conferences are located in the industrialised countries and there is a lack of high-level representation in the less developed areas, which impedes serious consultation, let alone negotiation. Problems of ldc participation are even more acute in respect to bulk carriers. At UNCTAD V, the industrialised countries voted against a Group of 77 proposal, adopted by the Conference, on bulk trades-which account for four-fifths of maritime trade, including most primary commodity carriage.

\section{Insurance}

An invisible item linked to the cost of Idc exports, is insurance. Many ldcs in recent years have strengthened the national character of their insurance markets. However, it is difficult to acquire control over the sector, because of such factors as shortages of finance and high-level skills, and the control exercised internationally by major companies based in the industrialised countries.

In some ldcs, state monopolies covering all insurance operations have been established; in others, insurance companies have been formed involving participation by the state with domestic and/or foreign private interests. It is becoming apparent, however, that the participation of foreign private companies, whether independently or jointly with local firms often creates a situation where control can be seized by the foreign partner, even if its equity holding is a minority one. An UNCTAD study notes that Bhutan, Burundi, Lesotho, and Rwanda have each recently established their own insurance companies with participation by the state and foreign private companies (UNCTAD 1977). The study draws particular attention to the situation in Burundi. The foreign group subscribed only 10 per cent of the registered capital of the company (CABU), but in exchange for technical services in the formation and operation of the new company (which will have a de facto domestic monopoly), the foreign minority partners have obtained a commission of 1.5 per cent on gross premiums, sole rights to place reinsurance, and 35 per cent of the company's reinsurance commission. As the UNCTAD study sums it up: 'Whatever the operating results of $\mathrm{CABU}$ may be, the foreign partners are sure of making a profit at the expense of national interest' (UNCTAD 1977: 1).

On the question of reinsurance, the volume of these services which the ldcs have purchased abroad to balance and protect their national portfolios has been increasing steadily since the establishment of national insurance industries (UNCTAD 1977: 10). Ldcs have reacted in a number of ways. Some of them have taken steps to encourage local insurers to retain a larger portion of the risks insured and to transfer abroad only the part really in excess of their retention capacity. However, some disaster-stricken countries have recently required their local insurers to increase the amount of reinsurance cover obtained abroad, highlighting the weakness of the insurance industry in these areas. The UNCTAD study points out that there is a number of internal agreements between international reinsurers, and these reinsurers can occasionally apply a cartel policy. The problems associated with the placing of reinsurance business abroad and those associated with foreign participation in local insurance companies are intertwined. The UNCTAD study notes 'there are cases in which the main object of such foreign participation is to obtain reinsurance business from the subsidiary company and to ensure that decisions concerning such reinsurance are not taken independently' (UNCTAD 1977: 26).

\section{Institutional Implications}

UNCTAD argues that the creation of a CSR system calls for concerted action in a number of interrelated areas. While detailed consideration needs to be given to the different activities and elements, "the interrelationships between them must be viewed as part of a comprehensive strategy' (UNCTAD 1979a: 4). UNCTAD seems particularly concerned about the distribution of costs and benefits which may arise from the separate elements of the ECDC programme. 'By pursuing simultaneously a large number of cooperation activities within a comprehensive framework', UNCTAD argues, 'it will help to ensure the widest possible distribution of benefits, since possible unevenness in distribution from particular activities can be counterbalanced by the pattern of distribution from others, with the result that a rough balance of equity can be attained without too much difficulty' (UNCTAD 1979a: 5). 
There are several approaches to institution building, all of which have both advantages and problems. Some argue that single-function groupings. such as a commodity cartel, are likely to fade away when the situation that gives rise to their formation has passed (Guetzkow 1971: 398-415). Then there is the problem that regional multifunctional groupings may inhibit the formation of global groupings. On balance, it would be advantageous to link the various operational approaches. Even though a number of ldcs might not be participants in all the various types of schemes, it is likely that all countries would belong to one or more cooperative scheme, such as producer associations, preference systems, multinational production and marketing enterprises, export credit schemes, regional banking groups, and schemes of subregional or regional economic integration. To preserve existing cooperative bonds and to encourage the development of new ones, the various schemes could be linked, even if only as negotiating groups for trading benefits within and between the various schemes.

Prospects for such collaborative schemes would be enhanced by the establishment of an organisation for Southern economic cooperation and development (OSCD), with its own permanent secretariat and research capability. Such an organisation could help to build unity out of diversity and with research support, stimulated by the objectives of promoting the development of the Third World, common negotiating positions on economic issues relating to NIEO could be elaborated at the various international fora. Regional groupings (for example, regional integration schemes) could act as intermediate linkage mechanisms. In this capacity, one of their main functions could be the negotiation of regionally-coordinated investment conditions for foreign firms and improved mechanisms for the transfer of appropriate technology. The existence of an OSCD should speed up the negotiation of generalised improvements in the international economic order (including various Codes of Conduct), but regional modifications to deal with specific regional and national problems can be best negotiated, and their implementation supervised, by regional bodies.

Finally, it would be very important to link the single-purpose groupings to national and local organisations to ensure the connection between CSR and national and local self-reliance. It should be easier for groups of ldcs with selfreliant approaches internally to agree on supranational equity in the distribution of the benefits of regional growth and Third-World-wide improvements to prevent polarisation among CSR participants.

\section{References}

Epstein, B. and K. Mirow, 1977, Impact on Developing Countries of Restrictive Business Practices of Transnational Corporations in the Electrical Equipment Industry: a Case Study of Brazil, (ST/MD/9), UNCTAD, Geneva

Guetzkow, H., 1971, 'Isolation and Collaboration: A Partial Theory of Inter-nation Relations', in Clagett Smith (ed), Conflict Resolution, University of Notre Dame Press, London

Newfarmer, R. S., 1978, The International Market Power of Transnational Corporations: A Case Study of the Electrical Industry, (ST/MD/13), UNCTAD, Geneva

UNCTAD, 1977, Insurance in Developing Countries: Developments in 1975-76, (TD/B/ C3/141), Geneva

--1978, The Marketing and Distribution System for Bananas, (TD/B/Cl/162), Geneva

-1978a, The Marketing and Distribution of Tobacco. (TD/B/Cl/205), Geneva

-1978b, The Marketing and Distribution of Cotton, (CD/Misc. 76), Geneva

-1979, Resolutions, Recommendations and Decisions Adopted at the Fifth Session, Manila, 7 May-3 June, (CA/1350), Geneva

-1979a, Economic Cooperation Among Developing Countries: Priority Areas for Action-Issues and Approaches, (TD/244), Geneva

-(1) 1979, see Editorial references 